$\overline{R e v i s t a ~ I b e r o a m e r i c a n a . ~}$ Vol. LXIV, Núms. 184-185, Julio-Diciembre 1998; 485-506

\title{
FEDERICO DE ONÍS Y EL CONCEPTO DE MODERNISMO. UNA REVISIÓN
}

\author{
POR \\ Alfonso García Morales \\ Universidad de Sevilla, España
}

A Susana Redondo, discípula de Onís

Hoy Federico de Onís se recuerda fundamentalmente por su monumental Antología de la poesia española e hispanoamericana (1882-1932), publicada en el Centro de Estudios Históricos de Madrid en 1934, en la que aparece expuesta su concepción del modernismo, que tanta repercusión ha tenido en los debates sobre el tema; y algo menos por la recopilación de ensayos España en América, que él mismo preparó veinte años después, al retirarse de la enseñanza en Columbia University, y que ha sido considerada prácticamente como unas obras completas. En realidad este libro sólo recoge lo más significativo de su obra escrita y ésta es, a su vez, sólo parte de una intensa labor cultural y educativa en España, Hispanoamérica y Estados Unidos, que hace de él una figura tan destacada como olvidada de la historia intelectual del mundo hispánico, relacionada con sus tendencias, instituciones y protagonistas más significativos de la primera mitad de siglo. ${ }^{1}$ El propósito de este artículo es interpretar la obra de Federico de Onís a partir del pensamiento nacionalista liberal español de esos años; reconstruir la formación de su Antología dentro de la tradición de antologías poéticas modernas en español; y dilucidar su contribución al debate sobre el modernismo como una respuesta a los problemas relacionados y agudamente sentidos por él de identidad y modernidad.

Simplificando algo, se puede decir que la biografia intelectual de Onís estuvo dividida en dos grandes etapas, una española de formación, entre 1885 y 1916, y otra americana de madurez, hasta su muerte en 1966; y que en cada una de ellas su reflexión histórico-literaria se dirigió a objetos diferentes, aunque inextricablemente relacionados: en la primera, la

\footnotetext{
${ }^{1}$ Aunque abundan las referencias indirectas, son pocos los estudios concretos sobre Onís. Desde su muerte han aparecido algunos volúmenes de homenaje, que valen sobre todo por los recuerdos personales de quienes lo conocieron: entre ellos los de Revista Hispánica Moderna, La Torre, Revista de Estudios Hispánicos y Universidad de Puerto Rico, a las que estuvo estrechamente vinculado. Conviene empezar citando la "Bibliografia de Federico de Onís" que Luis Arrigoitia realizó a partir de su archivo personal: según ésta, su obra escrita comprende 10 libros y 190 artículos sobre cultura, lengua y literatura española e hispanoamericana, 12 ediciones de escritores clásicos y modernos y 41 prólogos e introducciones (Unamuno en 229-262). Es importante continuar editando su epistolario, del que hasta ahora sólo se conoce el mantenido con Unamuno (Onís).
} 
cultura española y el Renacimiento; en la segunda, la cultura hispánica y el Modernismo. Esta segunda parte de su obra es la más personal e importante, por la cantidad, la calidad y la entonces novedad de sus trabajos; aunque una lectura conjunta deja ver que en ella Onís no hizo sino profundizar y ampliar considerablemente la anterior. Él terminó concibiendo al Renacimiento y al Modernismo como el principio y el final de la Edad Moderna, como épocas en las que la cultura hispánica logró dar carácter original y propio a un movimiento universal. "La originalidad de los pueblos y de los individuos - - escribió en 1949 — no se da en el aislamiento, sino en la comunicación con los demás, y precisamente estas dos épocas de máxima originalidad hispánica, son las de máxima comunicación de los pueblos hispánicos con el resto del mundo" (España en América 174). De esta manera Onís trató de resolver el conflicto entre lo español y lo europeo, entre la tradición y la modernidad, que está en la base de muchos de los problemas de identidad que experimentaron los intelectuales españoles de la época.

\section{Onís y sus maestros. El problema de España.}

El problema primero, en el sentido cronológico y de importancia, con el que se enfrentó Federico de Onís fue el por entonces ya antiguo pero muy vivo "problema de España", esto es, el problema de su decadencia, de su anomalía y postergación respecto a Europa. En sus años juveniles esta preocupación fue obsesiva, y aunque con el tiempo se hizo menos evidente, de ella deriva en realidad toda su labor intelectual. Al comienzo de sus memorias, escritas en tercera persona y como prefacio a España en América, Onís hizo recuento de su formación hasta 1908 y señaló sus tres maestros, Unamuno, Menéndez Pidal y Ortega, que de diversa manera proyectaron toda su energía sobre el tema común de España:

Nació en Salamanca el 20 de diciembre de 1885 y allí estudió en el Instituto y la Universidad hasta graduarse de Licenciado en Letras en 1905. Su principal maestro fue don Miguel de Unamuno, con quien tuvo relación íntima desde los seis años. En 1905 fue a Madrid a estudiar el año de doctorado, y entonces empezó su relación con su maestro don Ramón Menéndez Pidal, continuada en el Centro de Estudios Históricos desde su fundación. Entre tanto hizo oposiciones en 1907 al Cuerpo de Archiveros, Bibliotecarios y Arqueólogos, y fue destinado a León y en 1908 trasladado a Oviedo. Ese mismo año obtuvo el grado de Doctor en Letras, y conoció a su otro amigo y maestro José Ortega y Gasset, que acababa de regresar de Alemania y empezaba entonces a escribir (España en América 8).

En 1909 Onís era ya profesor y en 1911, catedrático de Lengua y Literatura Española de la Universidad de Oviedo, en la que desde el fin de siglo se reunía uno de los más activos núcleos krausistas, promotor del regeneracionismo en su vertiente universitariay americanista. Pese a que Onís no pudo dejar de reconocer la insustituible obra modernizadora del krausismo y muy concretamente de Francisco Giner de los Ríos y la Institución Libre de Enseñanza - por su impulso a la racionalidad científica, la secularización educativa y la pedagogía, el liberalismo político y el reformismo social-, nunca se sintió, como cabe deducir de su citado epistolario con Unamuno, personalmente unido al grupo ovetense. Su interés seguía estando en Salamanca y, cada vez más, en Madrid; con todo, tampoco dejó 
pasar la oportunidad que se le brindó en octubre de 1912 de pronunciar la conferencia de apertura de curso de la Universidad de Oviedo, que tituló "El problema histórico de la Universidad española" y que podemos considerar el inicio de su actuación "intelectual" y uno de los primeros e ignorados actos de presentación de la generación entonces ascendente, que terminaría conociéndose como la "Generación del 14".

En ella Onís comienza haciéndose eco del estado de ánimo de la juventud española: "Para el español el sentimiento de patria es esencialmente dolor"; "huérfanos de cultura [...] hace dos siglos que vamos a la rastra de Europa"; "Lo peculiar de España hoy - y el problema inminente que tenemos delante-, es que este pueblo nuestro no es un factor en las luchas por el avance de la civilización; que, dormidas o muertas sus energías, se ha quedado fuera de la corriente central de la historia moderna y sufre, en consecuencia, todos los males que se derivan de la falta de vida cultural" (España en América 55-57). Entre ellos, y muy específicamente, la ausencia de una auténtica Universidad. Pesimismo, pues, y europeísmo: "la diferencia que habría que salvar [...] es la que nos separa de la civilización europea contemporánea" (España en América 71). A continuación, en "La experiencia de un estudiante español", narra su propia educación. Empieza por Unamuno, el Unamuno de la primera madurez, junto al que había vivido los años universitarios en Salamanca, de quien había aprendido un espíritu siempre crítico y también, entonces, un europeísmo del que, sin embargo, el maestro había empezado a renegar cada vez más abiertamente después de 1905, razón por la que, creo, el discípulo se siente entonces lejos de él, incluso enfrentado intelectualmente, nunca en lo personal:

Los años que han pasado desde entonces hasta ahora me han hecho llegar a pensar de manera opuesta diametralmente a la suya, y a estimar de muy diferente modo el valor de sus ideas; pero no a perder ni un ápice del cariño que supo despertar en mi corazón [...]; una personalidad extraordinaria cuya influencia, si bien decisiva y redentora, por lo mismo de ser única y marcadamente personal, sólo es beneficiosa cuando sirve de paso para ensanchar el campo de las influencias (España en América 60, 64).

Estas distancias, estas nuevas influencias están marcadas por el magisterio de Menéndez Pidal y de Ortega y Gasset, cuyas enseñanzas buscó deliberadamente una vez terminada la carrera, alrededor de los que se había consolidado ya un grupo de discípulos y a los que veía como ejemplo de lo que podía y debía ser la Universidad futura, y a través de ella, la nueva España.

En Menéndez Pidal, con quien aprende la técnica de la fïlología, lo científico se une - dice- a "un espíritu moderno y progresivo y una fe tal en la cultura, que le mueve a consagrar lo mejor de sus energías no tanto a su producción personal como a la formación de nuevos científicos; y - caso rarísimo en España - ha llegado a crear a su alrededor un grupo de discípulos que empiezan a darse a conocer, logrando así la continuidad de su labor científica, único modo de que ésta sea fecunda" (España en América 63). En efecto, en 1907, por influencia de la Institución Libre de Enseñanza, se creó la Junta para la Ampliación de Estudios e Investigaciones Científicas (JAE), el organismo clave en la modernización de la cultura española hasta la Guerra Civil, dedicado a fomentar las relaciones internacionales a través de una política de pensiones a estudiantes y profesores en el extranjero, y la 
investigación mediante la creación de instituciones científicas y educativas. Entre sus instituciones científicas hay que citar la fundación del Centro de Estudios Históricos (CEH) en 1910, dirigido por Menéndez Pidal, que también tenía a su cargo la más importante de sus secciones, la de Filología. Onís formó parte de su promoción más antigua, junto con Américo Castro, Amado Alonso y Navarro Tomás, a los que se unieron posteriormente Pedro Salinas, Dámaso Alonso, Rafael Lapesa y los hispanoamericanos Alfonso Reyes y Pedro Henríquez Ureña, entre otros. Entre las instituciones educativas, se creó, también en 1910, la Residencia de Estudiantes, de la que Onís fue Director de Estudios. Durante casi tres décadas estos y otros organismos relacionados contribuyeron decisivamente a formar elites intelectuales, elevar el nivel científico, romper el aislamiento, crear, coordinar y dar continuidad a la alta investigación en España, fundar la filología en un sentido amplio, revisando la historia y la literatura, siempre en busca de la tradición, el espíritu o el carácter diferencial español, y enlazar el mundo académico y el creador. En 1932 Onís habló de la JAE y los centros que de ella dependían como "la verdadera y única universidad española" (España en América 66). Sin embargo, sus comienzos fueron difíciles y se la atacó desde distintas posiciones y ámbitos, entre ellos la propia Universidad anclada en el pasado. El mismo Unamuno, Rector de Salamanca, se unió ocasionalmente a las críticas, lo que provocó una respuesta durísima de Onís, quien en nombre de sus compañeros, le escribió en marzo de 1912, medio año antes del discurso en Oviedo:

\begin{abstract}
Creo que el Centro de Estudios Históricos, organismo oficial tanto como cualquiera de las Universidades, puede hacer y ha hecho ya por la cultura española más que lo que todas las Universidades juntas han hecho en los tres últimos siglos [...] ¿Le parece a V. que lo más grave y vergonzoso que ocurre en España es que nosotros estemos trabajando en el centro histórico y creemos la filología española? ¿No puede V. gastar sus energías preciosas más que en esto, en combatirnos a nosotros, en hacer atmósfera para que no vaya nadie al extranjero, en vez de atacar a la podredumbre universitaria ? [...] ¿Por qué, como rector de la Universidad, no ha logrado $V$. que hasta la fecha dé la menor señal de vida científica? [...] V. me infundió todas esas ideas; pero ha tomado V. un rumbo por el que no puedo seguirle" (Unamuno en 89).
\end{abstract}

Leyendo estas líneas se entiende mejor su discurso, su ataque a la Universidad desde dentro de la Universidad y, en parte, sus distancias respecto a Unamuno. En parte, porque este distanciamiento, que no ruptura, tuvo mucho de general, de "generacional" y fue como un episodio lateral del enfrentamiento, más importante y conocido, que acababan de protagonizar Unamuno y Ortega, un enfrentamiento que Onís vivió de cerca y del que, tras la muerte de ambos contendientes, dio una versión personal en "Ortega, joven" (1956). Ortega, sólo dos años mayor que él, también se había iniciado mostrando su adhesión a Unamuno, al "despertador" de las inquietudes juveniles en el páramo español, pero desde 1907 comenzó a acumular reservas que se tornaron abiertas diferencias dos años más tarde. Por encima de razones personales y de la lucha por la jefatura intelectual, la insatisfacción primero, el desacuerdo después que sintió Ortega ante el cariz tomado por Unamuno se debió a la cada vez más extremada posición irracionalista, mística de éste, a su creciente antieuropeísmo - él que había sido uno de los defensores de la europeización-, a su buscada "excentricidad", a su desprecio, más que falta de centralidad; una actitud, tal vez 
nacida del espíritu de contradicción, pero que en un medio intelectual tan menesteroso como el español le parecía una grave irresponsabilidad. No se podía estar de vuelta de Europa sin haber ido. En 1910 para Ortega, como para Onís, el problema era España y la solución, Europa (y "Europa" significaba antes que nada "ciencia"); y si por una parte veía a Europa como condición, como exigencia para España, también esperaba que ésta llegara a ser una ampliación, un enriquecimiento, una posibilidad europea. Ese año, el de la fundación del CEH y la Residencia, con los que mantuvo vínculos muy estrechos, ocupó la cátedra de Metafísica en la Facultad de Filosofía de Madrid y desde ella y otros medios comenzó a ejercer una influencia que fue reconocida así por Onís en su discurso: "También a su alrededor se ha formado un núcleo, cada día más creciente, de jóvenes en cuyo espíritu se entrelazan dos anhelos como algo inseparable: poseer la cultura europea y realizar la salvación de España" (España en América 64). Él mismo formó parte de este núcleo y compartió esos anhelos, lo que le hizo participar en dos proyectos orteguianos: en $1914 \mathrm{se}$ inscribió en la "Liga para la Educación Política Española", en la que el filósofo hizo un llamamiento a su generación para la revitalización de la nación y el impulso del liberalismo; y durante 1915 colaboró ocasionalmente en la revista España, creada originalmente como órgano de expresión de la Liga. Para entonces Onís también había vuelto a acercarse a Unamuno desde una posición de independencia, desde la mayoría de edad intelectual, había vuelto a aceptarlo con todas sus contradicciones, en las que con el tiempo vería algo propio no sólo de su carácter sino del modernismo.

Años después, Angel del Río y Mair José Bernardete, colegas de Onís en Columbia University, lo incluyeron en una antología sobre ensayistas preocupados por el tema de España, y lo presentaron como un resultado de sus experiencias y maestros juveniles:

La amplia curiosidad intelectual, el individualismo y la pasión por los problemas de España, que heredó de Unamuno, su primer maestro en las aulas de Salamanca, se disciplinaron en él mediante el rigor científico aprendido en Menéndez Pidal y el sentido europeo, jerarquizante, objetivo, nota esencial de los hombres de su generación, cuyo máximo representante es Ortega y Gasset, su amigo de juventud. Colabora con todos, tomando algo de cada uno sin dejar de ser él mismo. En su obra quedan reflejos de esas diversas experiencias.Tuvo, sin embargo, desde el principio, posición propia que se intensifica desde su salida de España (618).

¿En qué consistía esta "posición propia”? Dentro de la preocupación por la historia de España y de la "actitud teórica", de la aspiración a superar la mera erudición decimonónica y llegar a nuevas síntesis interpretativas, y de la frecuente colaboración en tareas de equipo, que se han reconocido como generales a los jóvenes discípulos de Menéndez Pidal, cada cual se dirigió a un campo específico. En un principio Onís optó por la historia moderna, y más concretamente por el Renacimiento que, a diferencia de la historia medieval que Pidal había empezado a construir sobre bases seguras, estaba completamente por hacer. En enero de 1912 le había escrito a Unamuno, con un tono que deja ver el carácter de sacerdocio patriótico y científico con que asumieron su labor los fundadores del CEH: "A mí, concretamente, lo que me interesa es el problema estrictamente científico de la historia de España; y a él consagraré mi vida [...]; me dedicaré de lleno a estudiar con riguroso método 
histórico el renacimiento español" (Unamuno en 86). El término y noción de Renacimiento, de por sí controvertida en toda Europa, se unió en España a la omnipresente cuestión de su identidad. "El problema histórico de la Universidad española" termina con una pregunta: ¿qué ha pasado para que en España no pueda haber Universidad?, y con esta reflexión general: el problema de la historia de España, de su decadencia, radica en su historia moderna, en la forma en que se manifestó en ella la crisis del Renacimiento. Onís partió de una idea entonces muy extendida: el Renacimiento como movimiento no existió en España, de ahí la ausencia de civilización europea, de cultura y de Universidad moderna; idea de la que sin embargo se iba a apartar inmediatamente. Entre los aislados esfuerzos modernizadores de la Universidad española cita a dos figuras salmantinas: Fray Luis de León y Diego Torres de Villarroel, a quienes estaba en ese momento dedicando sendas ediciones en la colección "Clásicos Castellanos", que desde 1910 lanzaba la editorial La Lectura, íntimamente relacionada con el CEH. Antes de terminar 1912 salió su ensayo introductorio a la Vida de Torres de Villarroel (España en América 348), en la que situaba a éste dentro de la cultura española del XVIII: "Lo característico de su tiempo sería, pues, ausencia de cultura; y el valor de don Diego - y el de los demás escritores de este tiempo, llamados reformadoresconsiste en tener conciencia de ello" (348). Dos años después, la introducción, más ambiciosa y madura, a De los nombres de Cristo de Fray Luis, cuyo método apuntaba al utilizado por su compañero Américo Castro: "Se desinteresa de la forma para centrarse en la interpretación de la obra a partir de la historia cultural del momento en que se produce. Es una historia de ideas y de las realizaciones de estas ideas en forma literaria, convirtiéndose en el paso intermedio entre el positivismo y la estilística en los estudios literarios" (Portolés 94). Para Onís el valor y la originalidad de Fray Luis estuvieron en su lucha por lograr una integración armónica entre la culturas judaica, pagana y cristiana, en su esfuerzo -que él comienza a entrever como general a todo el Renacimiento en España - por mantener una "moderna espiritualidad católica", "por salvar los principios eternos y la tradición de la Iglesia, incorporando a ella todos los nuevos valores humanos que la nueva época había traído a la presencia de los hombres" (España en América 309). "Sagazmente apuntaba Onís, como punto de partida para la comprensión del Renacimiento en España, la tendencia a hermanar las corrientes contradictorias de la época en una forma armónica que él veía realizada literariamente en Fray Luis" (Río y Bernardete 618). Veremos que esta concepción se desarrolló hasta plantearse como tesis diez años más tarde; hasta entonces cambiaron muchas cosas tanto en los estudios sobre el Renacimiento como en la vida de Onís, pero en cualquier caso su trayectoria intelectual estaba marcada: la historia y la literatura moderna en España, cuya necesidad de estudio fue de los primeros en señalar, lo iría llevando hasta lo más contemporáneo. Desde 1914, en que también empezó a colaborar en la recién fundada Revista de Filología Española, se advierte el sentido de su orientación: "El Centro de Estudios Históricos - le escribe a Unamuno en mayo- avanza mucho en sus publicaciones, y ha empezado la publicación de una Revista de Filología Española (en el más amplio sentido de la palabra Filología), revista excelente, que nos dará una cierta personalidad internacional y contribuirá a que el conocimiento de nuestra historia que impere en el mundo empiece a formarse aquí por españoles y no fuera por extranjeros" (97), y en julio: "hay que reforzar a toda costa, la parte moderna; para esto se tropezará siempre con la falta de colaboradores pues no hay nadie que trabaje bien en la historia literaria del 
siglo XVI hasta hoy. Sin embargo queremos llegar hasta lo contemporáneo, aprovechando los medios que tengamos hasta que salga gente nueva" (100). Y esa fue la tarea que emprendió él mismo nada más salir de España.

\section{En los Estados Unidos. Hacia una construcción critica del modernismo}

Durante la Gran Guerra, los Estados Unidos entraron en una nueva fase de afirmación de su liderazgo mundial y de su penetración en Hispanoamérica, y su interés por el estudio del español y de la cultura hispánica, muy reducido hasta entonces, comenzó a crecer de manera imparable. Por su parte, ante las dificultades de llevar a cabo sus intercambios con la Europa en conflicto, y consciente de la creciente importancia de los Estados Unidos y de la necesidad de restañar definitivamente las heridas del 98, la JAE decidió volcarse hacia ese país. Ambas circunstancias se unieron para que en 1916, Federico de Onís, que había ido retrasando desde hacía años su salida al extranjero, llegase a Nueva York como representante de la JAE y del CEH, para reorganizar, a solicitud de Columbia University, los estudios hispánicos en plena ampliación. Su idea era estar sólo un año, pero obtuvo varias prórrogas hasta que en 1921 decidió instalarse definitivamente, primero como profesor dentro del Departamento de Lenguas Romances, y entre 1929 y 1952 como Jefe del Departamento Hispánico, convirtiéndolo en uno de los más estables e importantes focos del hispanismo internacional. Allí publicó la mayor parte de sus escritos y llevó a cabo distintos proyectos, entre los que destaca muy especialmente la fundación en 1920 y la dirección entre 1930 y 1954 del Instituto de las Españas, rebautizado en 1940 Hispanic Institute, con el propósito esencial de promover lo que el hispanista de Columbia y también fundador del Instituto, William R. Shepherd llamaba "las relaciones triangulares" entre España, Hispanoamérica y los Estados Unidos. Margarita Ucelay estudió los orígenes e historia, organización, fines, socios, actividades y publicaciones del Instituto. Sólo recordaré que éste mantuvo una relación muy estrecha con la vida cultural española hasta la Guerra Civil y más tarde, con los intelectuales y artistas del exilio; especialmente con el CEH y con otros centros vinculados, como él, a este organismo madre: el Instituto de Filología de Buenos Aires, fundado en 1923 por Américo Castro y dirigido por Amado Alonso desde 1927; y sobre todo el Departamento de Estudios Hispánicos de la Universidad de Puerto Rico, que Onís ayudó a fundar junto a Navarro Tomás entre 1926 y 1928 (Formentín y Villegas 91156, 193-331). Una de sus primeras actividades fue organizar viajes de profesores y estudiantes norteamericanos a los cursos del CEH y la Residencia de Estudiantes. A su vez, muchos españoles pertenecientes a estos centros visitaron Nueva York como becarios, conferencistas y profesores; la estancia de Federico García Lorca durante el curso de 192930 es tal vez el caso más famoso, pero ni mucho menos el único. Paralelamente se llevaron a cabo numerosas actividades editoriales, musicales y teatrales; y se estableció una biblioteca, un fichero bibliográfico y varios archivos sobre literatura, música y folkore hispánico, los más completos en su género de la época.

El solo hecho de salir, más aún de permanecer tanto tiempo fuera de España, hizo que la preocupación de Onís por ésta, lejos de disminuir, se hiciese más amplia y profunda. "La verdad - decía en 1920- es que nunca como ahora me he sentido tan cerca de España [...] No hay experiencia tan honda como la de una larga estancia en el extranjero" (España en 
América 679-680). Al año siguiente le escribía a Unamuno: "Me preocupa ahora sobre todo nuestra América y España vistas desde aquí" (Unamuno en 118). Y en mayo de 1922: "Me es cada vez más difícil enterarme de lo que pasa en España; pero no me pesa, porque quiero conservar un poco la serenidad para poder ver algo de la España eterna" (Unamuno en 121). Su mitificación de la "España eterna", de "lo español"-en un sentido amplio que abarcaba, además de su Castilla natal, lo peninsular en sus distintas culturas regionales, incluido lo portugués, lo Hispanoamericano en toda su variedad, y hasta lo sefardita - se basaba, en el fondo, en una tácita identificación de esta imaginada realidad esencial con la tradición, la espiritualidad de Occidente, frente a Europa, que representaba la modernidad histórica, el progreso material. El futuro estaría en la síntesis, en una integración de ambas concepciones, en un progreso que fuera tanto material como espiritual. "Ningún progreso será fecundo si no nace de un impulso genuino de nuestra tradición”, escribe en 1927 (España en América 102), y son estas nuevas ideas las que le llevaron a matizar definitivamente su concepción de Renacimiento y sus ideas sobre la "europeización".

En 1926, un año después de que Américo Castro publicase El pensamiento de Cervantes en el CEH y Aubrey F. G. Bell, Luis de León. A Study of the Spanish Renaissance en Oxford, Onís expuso ante la Modern Language Association su tesis "El problema del Renacimiento aplicado a la literatura española", donde por distintas vías llegaba a la misma conclusión que ellos. Frente a las opiniones de otros estudiosos europeos, de él mismo en sus comienzos, Onís defendía la existencia de un Renacimiento español análogo, aunque peculiar y en ciertos aspectos superior al del resto de Europa: desde 1492 a 1536 España se transformó y adelantó a otros países por obra de fuerzas nuevas, renacentistas o modernas, como su precozmonarquía absoluta o el descubrimiento de América. Onís también aceptaba ahora sin problemas que España no había roto por completo con la Edad Media, sino que logró conciliar lo medieval y lo renacentista, como en el original arte plateresco o en la singular pervivencia de la poesía tradicional:

Ese fue, en general, el espíritu de España en esta época: el de la conciliación de la tradición y el progreso, de la autoridad y la libertad, de la Edad Media y el Renacimiento [...]; el espíritu de conciliación y armonía, que es la nota dominante del Renacimiento en España, es al mismo tiempo la nota más elevada del Renacimiento en general (España en América 295).

No sólo eso, la crisis de la idea de progreso que volvió a sentirse con especial agudeza en la Europa de entreguerras, lo llevó incluso a afirmar que el intento realizado por España de salvar en su Renacimiento los valores tradicionales, medievales y católicos, que él parece entonces identificar con valores humanos y espirituales, podía ser tomado como un ejemplo, como una vía de salvación para el futuro de la humanidad. Así lo expuso en su reseña al citado libro de Bell, publicada en la Revista de Filología Española en 1926, y de forma aún más rotunda en el prólogo a Ensayos sobre el sentido de la cultura española, publicado en la Residencia de Estudiantes en 1932:

Cada vez se ve más claro por los mismos pensadores de esos pueblos de Europa creadores de la civilización moderna, que ésta significa en gran medida un extravío y una desviación 
que la conducirán a su agotamiento y su muerte, y para evitarlos se siente cada vez con más fuerza la necesidad de volver al cauce más amplio y más humano de la Edad Media y del catolicismo [...] la actitud de España entonces encierra para nosotros, y para los europeos mismos, el valor de ser el intento y el ejemplo previos de un ideal de civilización moderna destinado a realizarse y a triunfar en el porvenir (España en América 44).

Con este último libro Onís dio prácticamente por concluido no su interés, pero sí sus publicaciones sobre el Renacimiento español y se centró definitivamente en la literatura española e hispanoamericana contemporánea, a la que había ido dedicando cada vez más atención desde su llegada a los Estados Unidos. No hace falta señalar las posibilidades de esos campos de investigación entonces casi vírgenes, que él pronto vislumbró y que su situación privilegiada en Nueva York - “cada vez más el centro de comunicación con las otras Américas" (España en América 9)--, sus visitas continuas a los países hispanoamericanos y sus nuevas obligaciones profesionales le ponían al alcance de la mano. Más tarde insistió, acaso retrotrayéndolo algo, que su interés por la literatura hispanoamericana se debió a Unamuno, quien, efectivamente, fue de los primeros intelectuales españoles en tomarla en consideración: "Ya antes de salir de España sentía la atracción de la América española como razón última del ser histórico de España. Mi trato con Unamuno me había preparado para conocerla, y ésta es quizá mi mayor deuda para con él" (España en América 9). En su acercamiento a la cultura hispanoamericana, Onís buscó de nuevo una solución conciliatoria que le permitiese afirmar tanto la españolidad como la originalidad de América. Esta solución, esta tercera vía la encontró gracias al concepto de "tradición viva", que él también quiso atribuir a Unamuno, aunque es propio de todo pensamiento paradójico o armonizador: "la verdadera tradición que, como largamente mostró Unamuno, es algo vivo y vivificador que se transmite como un fermento creador y mantiene a través de todos los cambios la unidad y persistencia de las culturas" (España en América 14). La tradición viva española es lo que explica para Onís "La eternidad de España en América", ensayo de 1942 en el que resume sus ideas sobre el asunto y que encabeza la compilación - ahora el título se entenderá mejor-España en América:

La permanencia de España en América tendremos que buscarla, por lo tanto, no como peso muerto o resto arqueológico del pasado, sino como fermento vivo latente en las creaciones nuevas y originales americanas; no en lo que España hizo y dejó en América, sino en lo que los americanos crearon por sí mismos diferenciándose de los españoles. Y será más patente y valiosa la tradición española de América si la encontramos en las creaciones americanas que más se diferencian de las españolas (15).

Y es desde esta posición desde la que enfocará la literatura moderna e hispanoamericana. Si para él los más grandes escritores españoles son los que han sabido modernizar la tradición - "sólo en lo nuevo vive lo antiguo y que los escritores originales que abren nuevos rumbos son los depositarios y conservadores de la tradición" (España en América 360-1) - los más grandes hispanoamericanos son aquéllos en los que, pese a su originalidad, incluso a su aparente antiespañolismo - Sarmiento o Martí, tan admirados por Unamunomás vigorosa es la tradición española. 
Aunque fue fundamentalmente autor de ediciones y estudios dispersos de numerosos escritores desde el modernismo, a algunos de los cuales descubrió - como a Gabriela Mistral, a quien publicó su primer libro, Desolación, en 1922 - o dio por primera vez tratamiento académico, Onís siempre se esforzó, tal como había aprendido en el CEH, en construir una historia literaria de ese periodo, en encontrar su unidad y ofrecer una síntesis; sobre todo a medida que iba creciendo en todo el mundo hispánico la conciencia de su importancia: en Hispanoamérica el modernismo era el comienzo de su literatura verdaderamente "independiente"; y en España, el comienzo de un "nuevo Renacimiento" literario y cultural, lo que para él significaba algo más que una metáfora. Ya en 1923 publicó tres artículos - "El problema de lo contemporáneo", "La España de la Restauración", "Carácter general de esta época"- destinados a un libro sobre literatura española contemporánea que nunca terminó, pero en los que apunta al menos tres rasgos esenciales de su visión unitaria de esta época. En primer lugar se trata de una etapa especialmente marcada en España por la preocupación sobre la identidad, "en la que este problema único y esencial de España ha llegado a ser más vivo, más agudo y más imperativo que nunca antes" (España en América 364); preocupación que dió lugar a la tajante división entre "dos Españas", una extranjerizante, con los ojos puestos en Europa y otra nacionalista, anclada en el pasado. "Entre las dos habrían acabado por destruir a España, si no hubiera sido porque desde el siglo XVIII para acá ha habido una tercera clase de españoles que a fuerza de ser originales han logrado fundir en sus espíritus lo europeo y lo tradicional y producir obras españolas de valor humano y universal" (365). Es entre esta tercera clase de españoles, cuyo linaje alguna veztrazó: "reformadores, progresistas, krausistas, institucionistas, modernistas" (España en América 14), entre los que sin duda él mismo se situaba. En segundo lugar, constituye una etapa de radical importancia literaria tanto en España como en América, por lo que afirma la necesidad de estudiarla a partir de la selección y ordenación de los muchos y confusos materiales de la época: "Este es el momento oportuno de incorporar a la historia de la literatura española toda una época brillante que empieza ahora a cerrarse cristalizada ante nuestros ojos: la literatura de los últimos treinta años, que ha producido en España y en América tal número de grandes escritores que puede considerarse sin duda como uno de los momentos más intensos y originales de la larga historia del espíritu español" (España en América 359). Finalmente señala que pese a la peculiaridad que presenta en el mundo hispánico, cabe considerarla como una época propia de toda la cultura occidental, cuyas causas son hondas y no se limitan a la literatura, sino a todos los órdenes. Incluso parece intuir algo que desde una perspectiva actual acaso resulte más claro, que el origen de lo que hoy llamaríamos la modernidad intelectual y estética nace, al menos en parte, como una respuesta a los problemas planteados por la modernidad histórica representada por la idea decimonónica de progreso. De ahí que ya diga que la época contemporánea es "uno de esos momentos en que los individuos sienten el vacío y el desengaño de una forma de civilización llevada hasta su última perfección y agotamiento y por lo tanto la necesidad de volver a empezar la construcción social sobre fundamentos nuevos" (369). De esta manera Onís establece la motivación y los criterios en los que basará su antología, e incluso esboza la concepción de modernismo que tratará de dilucidar en ella y en sus trabajos posteriores. 


\section{La Antología del 34.}

1934 fue un año importante para Onís. Comenzó a dirigir desde el Instituto de las Españas la Revista Hispánica Moderna, cuyo mismo título indica su nuevo y definitivo campo de interés (Sobejano y Redondo 222-230); y publicó la Antología de la poesía española e hispanoamericana (1882-1932), su obra máxima. Se trata de una antología muy extensa -más 1200 páginas-, de carácter histórico y crítico, con un denso prólogo en el que, junto a las intenciones y al plan general, se expone el concepto y la evolución de la poesía modernista, así como una completa bibliografía general y ajustadas notas y bibliografías de y sobre cada uno de los 164 poetas seleccionados. Su publicación en el CEH es un fruto más de la colaboración de éste con el Instituto neoyorquino, pero sobre todo es un síntoma del nuevo reconocimiento académico - que Onís había sido de los primeros en proclamar y llevar a la práctica - de la poesía española e hispanoamericana desde el modernismo, una poesía "comparable tan sólo a la del siglo de oro por el número y calidad de sus poetas y por su poder de creación de formas, sentimientos y mundos poéticos nuevos" (Antología de la poesía, XVII). Cabe señalar en este sentido que, después de veinte años dedicada a los estudios de Edad Media y Siglo de Oro, la sección de Filología del CEH acababa de fundar en 1932 la revista Indice Literario. Archivo de Literatura Contemporánea, con Pedro Salinas como director y Guillermo de Torre y Vicente Lloréns entre sus redactores; y que en 1935 Américo Castro comenzó a dirigir Tierra Firme, dedicada a temas hispanoamericanos, dos líneas de investigación que la Guerra apenas permitió desarrollar (Lapesa 71-72).

Las primeras páginas del prólogo son un esfuerzo por descartar algunas caracterizaciones del modernismo que Onís considera parciales y equivocadas, antes de exponer su visión del mismo como época unitaria. Rechaza su consideración como escuela o modo poético determinado, uniforme y duradero, cuando en él caben todas las escuelas y modos, y sólo prevalece "el subjetivismo extremo, el ansia de libertad ilimitada y el propósito de innovación y singularidad - que son las consecuencias del individualismo propio de este momento" (Antología de la poesía, XIV). Más erıúneo aún resulta su identificación concreta con el rubendarismo, con ciertas formas y temas que ni siquiera caracterizan por completo ni son exclusivas de este autor, pues "Rubén Darío", como los demás grandes escritores modernistas, "lleva hondas contradicciones dentro de sí mismo, se rectifica constantemente a través de sus distintas obras y sólo puede ser definido por la unidad de su propia individualidad" (Antología de la poesía, XIV). También rechaza la idea frecuente de que el modernismo se caracteriza por el afrancesamiento, porque la influencia francesa no es nueva, ni única, ni exclusiva de las letras hispánicas en ese momento. Precisamente, subraya con cierto afán de paradoja, "es el momento en que éstas logran liberarse de la influencia francesa, dominante y casi única en los siglos XVIII y XIX, para entrar de lleno en el conocimiento, no sólo de las grandes literaturas europeas inglesa, alemana e italiana [...], sino de otras literaturas como la rusa, la escandinava, la norteamericana, las orientales y antiguas, las medievales y primitivas" (Antología de la poesía, XIV-XV). Pues lo que le interesa demostrar es que la influencia extranjera, de la que "Francia fue para muchos impulso y vehículo", dio como resultado "tanto en América como en España el descubrimiento de la propia originalidad, de tal modo, que el extranjerismo característico de esta época se 
convirtió en conciencia profunda de la casta y la tradición propias, que vinieron a ser temas dominantes del modernismo" (XV). He aquí de nuevo la solución conciliatoria entre lo ajeno y lo propio que había ensayado en su propuesta de Renacimiento. Finalmente hacer ver que el cosmopolitismo, la apertura a las literaturas extranjeras, no era peculiar de la cultura hispanoamericana de entonces, sino un rasgo universal; y que la atracción general por lo otro, por lo remoto y extraño fue un hecho que - como había adelantado hacía una década - caracterizó "en todo el mundo a los hombres que empezaron a reaccionar contra el siglo XIX y la civilización normal europea al sentirse insatisfechos y decadentes en el momento en que ésta se encontraba en pleno goce de su última perfección y consecuente agotamiento" (Antología de la poesía, XV). Y termina exponiendo su definición, tantas veces citada, de modernismo como expresión hispánica de la crisis de una época, la del siglo XIX, representada, no debería olvidarse, por la idea de progreso; como tampoco debería olvidarse que Onís habla desde un momento de gran incertidumbre histórica, el inmediatamente anterior a la Guerra Civil española y a la II Guerra Mundial:

El modernismo es la forma hispánica de la crisis universal de las letras y del espíritu que inicia hacia 1885 la disolución del siglo XIX y que se había de manifestar en el arte, la ciencia, la religión, la política y gradualmente en los demás aspectos de la vida entera, con todos los caracteres, por tanto, de un hondo cambio histórico cuyo proceso continúa hoy (Antología de la poesia, XV).

Como se puede deducir de lo dicho hasta aquí, aunque la obra de Onís no podía dejar de partir de sus propios intereses y de las circunstancias concretas de su tiempo, lo verdaderamente meritorio y fructífero para los estudios posteriores estaba en su valoración del modernismo, en su superación de interpretaciones estrechas y ya inservibles, y sobre todo en su intento de articularlo dentro de una concepción más amplia, de lo que hoy llamaríamos la "modernidad". Intento más que meritorio, repito, pero no del todo logrado, pues le faltó profundizar algo en las ideas y matizar los términos. Su Antología se quedó en la identificación tácita del modernismo con el concepto más amplio de modernidad; y aunque pareció entreverlo, no acabó de distinguir la primera como expresión o momento de la segunda, ni acabó de dilucidar las complejas relaciones dialécticas de la modernidad estética con la modernidad histórica, tampoco de plantear con total nitidez la modernidad como una "tradición contra sí misma", que llevó a la ruptura de la vanguardia con el modernismo. Todo esto es lo que harían estudiosos posteriores, que en el mundo hispánico, sin embargo, no han podido dejar de partir de él. Desde esta concepción general, con sus logros y sus carencias, Onís planteó la selección, ordenación y caracterización concreta de los poetas de su Antología.

El gran aporte de material de la obra se explica por la labor bibliográfica que bajo su dirección se estaba llevando a cabo en el Instituto neoyorquino. Él mismo agradece la colaboración que desde allí le prestó la profesora Sidonia C. Rosembaum y desde el CEH, Vicente Lloréns y Juan Guerrerro Ruiz, quien por entonces también se ocupaba de la impresión de la Revista Hispánica Moderna; pero es de suponer que contó con el asesoramiento de otros colegas y de distintos poetas con los que tenía trato directo y continuado. Al menos sabemos de sus frecuentes intercambios de opiniones durante 1929 
con León Felipe, Angel del Río y Federico García Lorca, quien llegó a pasar en septiembre de ese año algunos días en su finca de New Jersey, ayudándole, según escribió Lorca a su familia, a seleccionar poemas de José Asunción Silva, Juan Ramón Jiménez, Salvador Rueda y otros menores (Rius 158-161; Meléndez 31; Gibson 53-55; Maurer 67). Por la correspondencia entre Jorge Guillén y Pedro Salinas también sabemos que en 1931 ambos estaban al tanto del plan de la antología; en enero Guillén escribía irónicamente a su amigo, entonces en el CEH: "Parece que es el año de las antologías. De una, la de Onís, ya sabrás mejor que yo, puesto que tienes al lado a su autor. Es antología de la RAZA, aunque él la llame modestamente de la poesía" (en Soria Olmedo 34). Pero fue sobre todo Juan Ramón Jiménez, amigo personal de Onís desde los años en la Residencia de Estudiantes, quien siguió más de cerca la elaboración de la obra. Según el citado Guerrero Ruiz, íntimo del poeta, cuyas conversaciones recogió en un diario, ambos revisaron la Antología en 1931 y Juan Ramón le contó haber influido sobre Onís para que fuera más estricto en su selección: "Creo que ha cogido bastante de lo que yo le he dicho y habrán caído unos treinta poetas que no debían figurar. El me ha dicho que yo veo las cosas como poeta, que sólo considero lo selecto, y que él ha de verlas como historiador, de un modo histórico" (Guerrero 153). Aunque creo que Juan Ramón, más que influir, en realidad fue influido por la Antología y probablemente fue el primero que partió de ella para elaborar buena parte de su propia concepción del modernismo, que apareció ya claramente formulada en una entrevista concedida a comienzos de 1935, nada más publicado el libro:

El Modernismo no fue solamente una tendencia literaria; el Modernismo fue una tendencia general. Alcanzó a todo [...]; no es cosa de escuela ni de forma, sino de actitud. Era el encuentro de nuevo con la belleza, sepultada durante el siglo XIX por un tono general de poesía burguesa. Eso es el Modernismo: un gran movimiento de entusiasmo y libertad hacia la belleza (Río 138).

En adelante Juan Ramón no hizo sino repetir, matizar y desarrollar de forma muy personal esta declaración. Allí está el núcleo de su concepción, no muy lejana a la de Onís: el Modernismo es una tendencia global, no sólo literaria, consistente en una vuelta a la Belleza. Esta vuelta hay que entenderla, en su sentido general, como una regeneración humanista, una recuperación de los valores espirituales y estéticos frente al materialismo del mundo moderno. $Y$ en su sentido literario, como una renovación verbal, hecha de libertad y exigencia, que enlaza con lo que él cree ser la más auténtica tradición poética española. ${ }^{2}$

Tampoco fue muy explícito Onís a la hora de señalar los antecedentes de su obra. En el prólogo dice haberse propuesto continuar la historia y ordenación de la poesía en español en el punto en que lo habían dejado la pionera Antología de poetas hispanoamericanos, de Marcelino Menéndez Pelayo, publicada en 1893, y el Florilegio de poesías castellanas del siglo XIX, de Juan Valera, publicada en 1902-1903, esto es, en los mismos años en que se iniciaba la "revolución" modernista. Y más adelante: "Antes de ahora se han hecho antologías nacionales de la poesía contemporánea, algunas excelentes y otras que no lo son

\footnotetext{
${ }^{2}$ La concepción del modernismo de Juan $\mathrm{R}$. Jiménez en sus distintas formulaciones ha sido muy bien estudiada, entre otros, por Ricardo Gullón, Angel del Río y F.J. Blasco Pascual, aunque me parece necesario insistir más en su conexión con la de Onís.
} 
tanto; sus méritos nos son bien conocidos, y nadie debe alabarlos y agradecerlos más que yo por la gran ayuda que me han prestado en mi labor"'(XXII). No nombra a ninguna, aunque las recoge prácticamente todas en la bibliografia. Pero si se comprueba esta lista y se tiene en cuenta el artículo "Anthologies of the New Poetry" que él publicó en 1927 y nunca recogió en libro, tal vez pueda establecerse la verdadera filiación de su obra dentro de la intrincada genealogía de antologías modernas en español. En ese artículo Onís había vuelto a insistir en que si se quería juzgar el valor individual de los nuevos poetas hispanoamericanos era imprescindible ordenar la poesía de esos países en los últimos treinta años, la más importante de su historia. Muchos, especialmente los primeros de esos poetas eran ya reconocidos en todo el mundo hispánico:

Those poets belonging to the first generation of the present epoch, men like Gutiérrez Nájera, Casal, Silva, Rubén Darío, Amado Nervo, Herrera y Reissig, Chocano, Valencia, Lugones, Urbina, González Martínez, Jaimes Freyre, Armando Vasseur, Blanco Fombona, and others are familiar to all Spanish-speaking readers. Some of these poets, especially those who have died, have acquired the rank of classics, but all of them were known before 1900, and the life and production of some had ended before that date (Anthologies of the 169).

Por contra, la producción de los poetas siguientes, "the poets of the twentieth century", apenas era leída más allá de sus propios países, con la excepción de la de Gabriela Mistral, y no porque supusiera un decaimiento respecto a la anterior, sino por su misma abundancia y variedad. $Y$ eran precisamente las diferentes antologías nacionales las que habían comenzado a darla a conocer y clasificarla. Entre estas antologías Onís cita concretamente cuatro, publicadas, obsérvese, a partir de la muerte de Darío en 1916, esto es, cuando el modernismo era ya realmente historiable, y pertenecientes a países hispanoamericanos en los que la institución literaria era especialmente fuerte: la de Genaro Estrada Poetas nuevos de México (1916); la de Armando Donoso Nuestros poetas. Antología chilena moderna (1924); la de Félix Lizaso y José Antonio Fernández de Castro La poesía moderna en Cuba, 1882-1925. Antología crítica (1926) y sobre todo la de Julio Noé Antología de la poesía argentina moderna: 1900-1925(1926). Todas ellas, como dice con razón Onís, habían sido construidas con un "markedly national character" y eran "incomparably superior to the many anthologies heretofore published of Spanish-American poetry of the nineteenth century which, rather than clarifying, tended to keep the reader's mind in a state of confusion and ignorance" (Anthologies of the 170). Muestran la progresiva especialización de la crítica que había acompañado al crecimiento en cantidad y calidad general de la literatura hispanoamericana desde el modernismo, así como la consolidación de las distintas tradiciones literarias nacionales, que es tanto como decir de las distintas tradiciones literarias modernas, y presentan rasgos comunes:

Their common object is to collect the different aspects of their native poetry since modernism down to the most recent of the younger poets. They all give biografical and bibliographical information concerning the authors; and in every case the compiler has carried out his work with thoroughness, broad-mindedness and impartiality of judgment and a complete knowledge of his material (Anthologies of the 170). 
No otro es el propósito que él trató de llevar a cabo en la suya, pero aplicándolo por primera vez a todo el mundo hispánico. Incluso cabe pensar que pudo empezar a trabajar en ella por entonces, 1927, abandonando a cambio el proyectado libro sobre literatura contemporánea. Con todo, conviene añadir un dato. También Estrada, Lizaso, Fernández de Castro y Noé habían tomado conscientemente como modelos a prestigiosas antologías europeas y norteamericanas inmediatamente anteriores. Entre ellas hay que mencionar especialmente dos: Poètes d'Aujourd'hui, de Adolphe Van Bever y Paul Léauteaud, la antología de poesía francesa desde el simbolismo que se publicó en 1899 y que alcanzó numerosísimas ediciones, difundiéndose por todo Occidente y sirviendo de ejemplo a diversas antologías nacionales; y la antología de Enrique Díez-Canedo y Fernando Fortún La poesía francesa moderna, (1913), tan leída entonces por los poetas jóvenes del mundo hispánico. Además, creo necesario subrayar que más importante que la disposición externa común a todas estas obras, con aparato de prólogo, bibliografía y notas, y que la pretendida actitud distanciada, rigurosa, histórica y no parcial o militante de los antólogos, es el hecho de que todos ellos organicen su materia según tres secuencias temporales: la poesía del pasado, la poesía del presente, la poesía en la que despunta el futuro. Este esquema tripartito básico, que se concreta en variaciones muy diversas, es el que adoptó Onís y el que pervive hoy en la forma usual de entender la evolución de la poesía de la época según tres periodos: modernismo, posmodernismo, vanguardia. Me atrevería a decir que responde, entre otras cosas, al carácter narrativo que tiene toda historia, incluida la literaria: como en las demás narraciones, en ésta cuyo sujeto es la poesía moderna hay un comienzo, un desarrollo y un final y cada uno de estos momentos tienen sus héroes o poetas representativos (Lugones, Banchs, Borges por citar el conocido caso argentino). Y que también ayudaron a forjarlo las teorías sobre generaciones literarias que entonces empezaron a formalizarse, difundirse y aplicarse, según las cuales en todo momento histórico conviven tres generaciones: la que declina, la vigente y la emergente.

En el caso concreto de Onís los 164 poetas elegidos se distribuyen de acuerdo al siguiente índice: I- Transición del romanticismo al modernismo (1882-1896); II- Rubén Darío; III- Triunfo del modernismo (1896-1905); IV- Juan Ramón Jiménez; VPosmodernismo (1905-1914); VI- Ultramodernismo (1914-1932). A primera vista la variación más peculiar del esquema parece estar en la adjudicación a Darío y Juan Ramón de sendas secciones unipersonales, aunque el procedimiento ya lo había empleado Noé al comenzar su antología, la más cercana a la de Onís, con una sección exclusivamente dedicada a Lugones. Onís explica en el prólogo que la primera fase, enmarcada por las fechas del Ismaelillo de Martí y Prosas profanas de Darío, significó "un proceso de transformación y avance autóctono y original en lo esencial, que nació espontáneamente de la propia insatisfacción y necesidad interna de renovación, y se desarrolló coetáneamente con el simbolismo francés y los demás movimientos independientes y semejantes que brotaron en diversos puntos del mundo y se fecundaron mutuamente" (Antología de la poesia, XVI). Establece, además, sintética, casi tácitamente su posición respecto a dos puntos que, por razones fundamentalmente nacionalistas, han sido especialmente polémicos desde el comienzo de la crítica sobre el modernismo: la "prioridad" entre Hispanoamérica o España, y el papel histórico de Darío y su relación con los "precursores o iniciadores". 


\begin{abstract}
Aunque en España no falten intentos en el mismo sentido, esta transformación y avance hacia una poesía nueva fue obra de poetas americanos que, independientemente de España y en gran medida los unos de otros, en Méjico, en Colombia, en Cuba, en el Perú, de 1882 a 1895 renovaron la poesía en tal forma que, cuando el genio sintético de Rubén Darío llevó a España en su propia obra los frutos últimos y más maduros de aquella evolución poética, fue considerada como la primera contribución americana a la literatura de nuestra lengua (Antología de la poesía, XVI-XVII).
\end{abstract}

Es significativo el hecho mismo de elegir como punto de partida 1882 y no 1888 , la fecha de $A z u l \ldots$ de Darío, a quien sin embargo dedica una sección completa para reflejar "su posición única como unificador de la poesía americana anterior y como transmisor de su influencia a la poesía de España" (Antología de la poesía, XVII). Y son los años de Prosas profanas a Cantos de vida y esperanza los que señalan "el triunfo" de un movimiento en rigor breve pero enormemente fecundo. Al lector actual tal vez le sorprenda la inclusión en esta sección de varios "poetas regionales" - Vicente Medina o José María Gabriel y Galán- junto a los grandes modernistas americanos y españoles - Lugones o los Machado-, pero esto se debe al criterio histórico que preside la obra, a la popularidad que aquéllos alcanzaron en el cambio de siglo, y tal vez a la debilidad que por alguno de ellos sintió Juan Ramón Jiménez. Éste figura inmediatamente después, "como aquel en quien el modernismo, llevado a su máxima rectificación y depuración, se enlaza con la poesía de las generaciones posteriores" (Antología de la poesía, XVIII).

Pero lo verdaderamente singular de esta antología está en la siguiente etapa, "el posmodernismo (1905-1914)", que aunque ya había sido apuntada por la crítica, y en concreto por las antologías nacionales que hemos considerado como sus modelos, no había sido bautizada, caracterizada, inventada de la manera global en que lo hace Onís. El posmodernismo es "un intento de reaccionar contra el modernismo, refrenando sus excesos" (Antología de la poesía, XVIII) e incluye en él a 69 poetas, muchos de ellos declarados "menores", clasificándolos en los siguientes grupos: "modernismo refrenado (reacción hacia la sencillez lírica)"; "reacción hacia la tradición clásica", "reacción hacia el romanticismo", "reacción hacia el prosaísmo sentimental (poetas del mar y viajes, poetas de la ciudad y los suburbios, poetas de la naturaleza y la vida campesina)", "reacción hacia la ironía sentimental" y "poesía femenina". Puede que, como divisiones, sean demasiadas y poco claras -el propio Onís es, desde luego; consciente de lo arbitrario que resulta siempre encasillar a autores variados y cambiantes-, pero en todo caso son tendencias significativas y, en conjunto, sirven para caracterizar la poesía de esos años. Aún hoy, cuando el nombre "posmodernismo" se presta a confusiones, por la extensión del concepto y término (posterior y diferente) de "posmodernidad" y sus derivados, se puede decir que se ha avanzado poco en el conocimiento de este modernismo tardío y que la fuente máxima, a veces única, de información sobre bastantes poetas de entonces siguen siendo estas páginas. Cabría pensar que Onís, como Estrada, Donoso, Lizaso, Fernández de Castro y Noé, pertenece él mismo a la generación "posmodernista", de ahí que conozca mejor, privilegie y hasta cierto punto construya su antología a partir de ese momento. Y lo que es más importante, su tendencia a hacer sinónimos modernismo y modernidad y a valorar a los escritores que habían sabido asimilar las corrientes renovadoras extranjeras y fundirlas con 
la tradición española, lo llevó a subrayar la continuidad por encima del cambio, a soslayar algo las expresiones más rompedoras y cosmopolitas y sobre todo, a intentar integrar con dificultades la siguiente etapa, la vanguardista, que empezó presentándose precisamente como una negación del modernismo.

Pues si el "posmodernismo" es lo más característico de la Antología, lo más discutible es sin duda la denominación y el tratamiento del "ultramodernismo (1914-1932)", al que Onís concibe no ya como un intento de reaccionar contra el modernismo, sino "de superarlo, llevando más lejos aún su afán de innovación y de libertad" (Antología de la poesía, XVIII). Pero sus dudas son aquí constantes: a veces habla de "ultramodernismo", otras de "ultraísmo"; y lo considera tanto el final de una época como el principio de otra, o ambas cosas, pues "¿quién puede decir cuáles de las nuevas manifestaciones son producto del esfuerzo de la agonía o de la germinación; cuáles son, en una palabra, un principio o un fin?" (Antología de la poesía, XIX-XX). Al fin y al cabo, se trata de la parte más cercana a los hechos y a las polémicas. Después de que Noé publicase la primera edición de su antología en 1926, mientras él realizaba la suya, la historia literaria lógicamente no se había detenido. Siguieron apareciendo antologías en la que se presentaban a los nuevos escritores de vanguardia. En primer lugar antologías de grupo, como el Indice de la nueva poesía americana, de 1926, firmada por Alberto Hidalgo, Vicente Huidobro y Jorge Luis Borges; o la Exposición de la actual poesía argentina (1922-1927), organizada por P. J. Vignale y César Tiempo en 1927. E inmediatamente después, antologías históricas, en las que los nuevos escritores daban un paso más, se alejaban del vanguardismo militante y aparecían incorporados ya a la tradición, junto a los principales poetas desde el modernismo; entre ellas, otras dos fundamentales y extremadamente polémicas en sus respectivos países: la de Jorge Cuesta Antología de la poesía mexicana moderna (1928), representativa del grupo Contemporáneos, y la primera versión de la de Gerardo Diego, Poesía española. Antología, 1915-1931 (1932), representativa de la generación del 27. Onís no podía dejar de conocer las controversias que habían suscitado estas obras, especialmente la de Diego (Soria Olmedo 11-59), y, aunque en todo momento se presenta como un historiador neutral, se notan sus especiales precauciones al justificar la elección de los más jóvenes, limitada a unos pocos, aquellos que han publicado obras maduras antes de 1933: "Nuestro criterio, pues, ha sido mucho más restringido en esta sección que en las anteriores, y deseamos que esto se entienda así para que no se crea que hemos pretendido prejuzgar el valor de los poetas en formación" (Antología de la poesía, XXI).

Con todo, las primeras reseñas sobre la obra se mostraron - caso raro tratándose de una antología - casi unánimes en la alabanza, y sólo objetaron la última parte, sobre todo su denominación. Pedro Henríquez Ureña la saludó en La Nación de Buenos Aires, como "historia literaria de calidad excepcional" (43), pero se preguntó sobre el "Ultramodernismo": "¿Por qué [...] no le llama vanguardia, según es de uso, sino ultraísmo, nombre de significación limitada, histórica ya, que no resiste la aplicación a poetas como García Lorca o Jorge Guillén?" (41). Guillermo de Torre escribió una reseña en Revista de Occidente donde empezaba acumulando todos los elogios: a diferencia de las acostumbradas "antologías poéticas unilaterales", como la de Gerardo Diego, ésta es una "verdadera antología cabal y aun exhaustiva", que muestra "la amplitud acogedora y el tacto clasificatorio de Onís", su "lejanía, profesoralismo, ecuanimidad", que "empalma con los mejores modelos del siglo" 
y que es "hoy por hoy un repertorio lírico y bibliográfico insuperable; un verdadero instrumento de trabajo del que hasta ahora carecíamos y al que habrán de recurrir cuantos en adelante trabajen - profesional o desinteresadamente- sobre estas materias" (222228); pero termina: "La única [reserva] de cierta profundidad — susceptible incluso de ser planteada polémicamente - que pudiéramos hacer a Federico de Onís es de índole clasificatoria, nominativa" (231). Y a continuación se refiere al término "ultraísmo", acusando a Onís de "recoger el nombre y desdeñar la cosa, esto es, de excluir las muestras genuinas y expresivas de aquella modalidad poética" (231); de aplicarlo a algunos poetas de entreguerras, entre ellos a algunos españoles que hoy llamaríamos del 27, y olvidar "que la simple mención del ultraísmo va unida, en la memoria de todos, a un conjunto de poetas, no por pasajeros e inconsecuentes desdeñables para un historiador escrupuloso" (232). A un conjunto de poetas de los que, como es sabido, había formado parte el propio Guillermo de Torre, quien de esta manera inicia sus protestas contra "los escamoteos antológicos" (Historia 174-178), su vindicación contra la larga ocultación crítica del ultraísmo, causado en parte por el monopolio del 27 , y sólo roto a partir de los años sesenta, con la revisión de las vanguardias, paralela a la revitalización de los estudios sobre el modernismo.

\section{ULTIMAS REFLEXIONES SOBRE EL MODERNISMO.}

Federico de Onís nunca volvió a España después de la Guerra Civil; se concentró en su labor en Nueva York, siempre en contacto con otros exiliados intelectuales españoles y con distintas Universidades hispanoamericanas. En lo fundamental sus nuevos trabajos siguieron profundizando y matizando la misma concepción del modernismo expuesta en la Antologia, y por lo general fueron escritos a raíz de las distintas polémicas y celebraciones académicas surgidas en esos años. Tal vez lo primero destacable sea su temprana reacción ante el concepto de "generación española del 98", que Pedro Salinas y Hans Jeschke habían rescatado en 1934 para oponerlo a los de modernismo y modernismo hispanoamericano, difundirlo e iniciar así uno de los más pertinaces debates de la historia literaria española de este siglo. Sólo cuatro años después, en un ensayo sobre Manuel González Prada, Onís añadió entre las consideraciones erróneas sobre el modernismo la "otra denominación, también falsa por parcial, la de 'generación del 98'" (España en América 633) y volvió a abogar por una consideración epocal, amplia e integradora del mismo, que es la que, con matices, predomina hoy.

En 1952, cercana ya su jubilación, recibió la invitación de dirigir el Departamento de Estudios Hispánicos de la Universidad de Puerto Rico, que, como se dijo, él había ayudado a fundar un cuarto de siglo antes. Durante dos años llevó esta tarea a la par con la de Columbia; después y hasta su muerte se instaló de manera casi permanente en la isla. Fue con motivo de la jubilación en Columbia que quiso dejar terminado el Cancionero de Unamuno, el diario poético que éste había ido escribiendo desde 1928 hasta su muerte en el 36, y cuya publicación asumió como un deber filial, pero que no terminó hasta 1953. Ese mismo año, en las aulas de Puerto Rico, coincidió con Juan Ramón Jiménez, quien estaba dictando su conocido “curso sobre el modernismo" que Ricardo Gullón editó años después. No suele recordarse que, aparte de seguir desarrollando sus antiguas ideas sobre el tema, tan cercanas a las de Onís, Juan Ramón invitó con frecuencia a éste a sus clases y utilizó la 
Antología como texto principal de consulta. Tampoco debe olvidarse que en 1953 se celebró el centenario del nacimiento de José Martí, escritor y mito nacional de Cuba, pero de dimensiones continentales. Onís leyó en La Habana su conferencia "Martí y el modernismo", donde hizo una de las más largas exposiciones de sus ideas aplicadas a esta figura: Martí como hombre, pensador y escritor, es la primera encarnación hispanoamericana del modernismo en su sentido más amplio, y no es posible abordarlo a partir de "las concepciones parciales erróneas que se han convertido en lugares comunes" (España en América 623), como tampoco lo son los otros dos modernistas, tan diferentes, con quienes lo pone en relación y que además fueron los iniciadores de la valoración martiana: Darío y Unamuno. Onís, sin embargo, se sigue debatiendo incómodamente en su identificación completa entre modernismo y modernidad. De una parte reitera la valoración de Martí que hizo en la Antología, donde por un momento parecía diferenciarlos: "su modernidad apuntaba más lejos que la de los modernistas, y hoy es más válida y patente que entonces" (Antología de la poesía 35); de otra plantea, esta vez explícitamente, su equiparación: "Nuestro error está en la implicación de que haya diferencia entre 'modernismo' y 'modernidad', porque modernismo es esencialmente, como adivinaron los que le pusieron ese nombre, la búsqueda de la modernidad" (España en América 625).

También en el 53, casi treinta años después de haber leído en la reunión anual de la MLA "El problema del Renacimiento aplicado a la literatura española", expuso en el mismo foro el que puede considerarse como compendio de sus trabajos: "Sobre el concepto del modernismo". Comienza resumiendo las ideas confusas sobre ambas épocas, aquellas que pretenden reducir el Renacimiento a las influencias italianas y clásicas, y el Modernismo, a las francesas, sin tener en cuenta la originalidad y el valor de los productos hispánicos: "Ambas - Renacimiento y Modernismo-, una al principio y otra al fin de la Edad Moderna, son épocas de profunda originalidad en las que la cultura hispánica imprime carácter propio a un movimiento universal" (España en América 175); vuelve a rechazar la denominación de "generación del 98" por cuanto sustrae al modernismo español de la unidad del Modernismo hispánico y recuerda que "esa fecha de 1898, como todo lo tocante al Modernismo, tiene a la vez una significación española e hispanoamericana, y más hispanoamericana que española" (España en América 179-180), ya que significa tanto la terminación del imperio colonial español, como el comienzo de la expansión de los Estados Unidos en Hispanoamérica; y termina: para entender el modernismo "hay que desechar las interpretaciones parciales y, sobre todo, la de intentar reducirlo a una escuela rubendariana, en la que no cabrían Martí, ni Unamuno, ni el mismo Rubén Darío, y, en cambio, hay que mirarlo en su unidad y su conjunto, como una crisis espiritual que en múltiples formas individuales y nacionales diversas y aun contradictorias logró dar nueva expresión universal y moderna a lo más hondo del ser hispánico" (España en América 180-181).

Al año siguiente escribió "La poesía iberoamericana", en la que repite: "El modernismo - como el Renacimiento o el Romanticismo- es una época y no una escuela" (España en América 163); se pronuncia ante la polémica otra vez reavivada sobre los modernistas de primera generación como "precursores o iniciadores" y se hace eco del interés que a partir de ellos, y concretamente de Martí, empezaba a despertar la prosa modernista: "suelen llamarse precursores, pero en rigor son los creadores de la nueva literatura en el verso y la prosa" (163). Pero para Onís era ya la hora del recuento. En 1955 reunió el libro tantas veces 
citado aquí España en América, en el que incluyó, convertida en "Historia de la poesía modernista", la Antología de la poesía española e hispanoamericana (1882-1932) o, mejor, el prólogo y las notas sin las bibliografias y las selecciones de poemas, como había hecho Menéndez Pelayo con la suya. Después, en el 61, la reeditó completa en Las Americas Publishing Co. de Nueva York. De su producción restante sólo me interesa recordar su coordinación, bibliografia e introducciones a tres números de homenaje publicados por la revista La Torre de Puerto Rico, que en ese momento final debieron tener para él un sentido más que académico, personal. El primero, en 1961, dedicado a su siempre maestro Unamuno por el vigésimoquinto aniversario de su muerte; el siguiente, en el 64, a Antonio Machado, por el mismo motivo. En éste se refiere a su Antología y dice: "Hay un detalle en aquella antología que no está explicado y no se sabe lo que significa, y es el hecho de que al frente de dicha obra puse una dedicatoria que decía simplemente: A Antonio Machado [...] En mi dedicatoria había la intención inconfesada de hacer constar mi preferencia personal, mi predilección por su poesía", poesía "total e integral" (“Antonio Machado ..." 12-13). Su último trabajo lo escribió en 1967 , pocos meses antes de morir, con ocasión del centenario del nacimiento de Rubén Darío, a quien vuelve a situar dentro del modernismo, como "el símbolo de esa época", "una época como la del Renacimiento, en que la cultura española adquirió una profunda originalidad dentro de la cultura universal" ("Rubén Darío" 27). Por esos mismos años acabó de imponerse una visión del modernismo que Onís había sido de los primeros en proponer desde sus personales presupuestos y alcances: entenderlo dentro del amplio y complejo proceso de la modernidad histórica y literaria; una visión de la que partió la renovación de los estudios modernistas durante las décadas de los 70 y 80 y en la que básicamente nos movemos aún.

\section{Bibliografía}

Arrigoitia, Luis. "Bibliografia de Federico de Onís". La Torre (Homenaje a Federico de Onís). 229-262.

Blasco Pascual, Francisco Javier. "Introducción”a Juan Ramón Jiménez. Alerta. Salamanca: Universidad de Salamanca, 1983.

Centenario de Federico de Onís (1885-1966). Puerto Rico, Seminario de Estudios Hispánicos Federico de Onís, Oficina de Publicaciones e Investigaciones, Facultad de Humanidades, Universidad de Puerto Rico, 1985.

Cuesta, Jorge. Antología de la poesía mexicana moderna. México: Contemporáneos, 1928

Diego, Gerardo. Poesía Española. Antología, 1915-1931. Madrid: Signo, 1932.

Donoso, Armando. Nuestro poetas. Antología chilena moderna. Santiago: Nacimiento, 1924.

Estrada, Genaro. Poetas nuevos de México. México: Porrúa, 1916.

Formentín Ibáñez, Justo y María José Villegas Sanz. Relaciones culturales entre España y América: la Junta para la Ampliación de Estudios (1907-1936). Madrid: Mapfre, 1992.

Gibson, Ian. Federico García Lorca (2. De Nueva York a Fuente Grande, 1929-1936). Barcelona: Grijalbo, 1987 ( $\left.2^{\circ} \mathrm{ed}\right)$. 
Guerrero Ruiz, Juan. Juan Ramón de viva voz. Madrid: Ínsula, 1961.

Gullón, Ricardo. "Juan Ramón Jiménez y el modernismo". Juan Ramón Jiménez. El modernismo. Notas de un curso (1953). Madrid: Aguilar, 1962. 13-41.

Henríquez Ureña, Pedro. "Poesía contemporánea" (Reseña sobre la Antología de la poesía española e hispanoamericana de Onís, La Nación, 31 de mayo 1935). Obras completas, vol. VII. Santo Domingo: UNPHU, 1979. 39-43.

Lapesa, Rafael, "Menéndez Pidal, creador de escuela: el Centro de Estudios Históricos", AA. VV., ;Alça la voz pregonero!. Homenaje a Don Ramón Menéndez Pidal. Madrid: Cátedra-Seminario Menéndez Pidal, 1979. 43-79.

La Torre (Homenaje a Federico de Onís), XVI/59 (enero-marzo 1968).

Lizaso, Félix y José Antonio Fernández de Castro. La poesía moderna en Cuba, 1882-1925. Antología crítica. Madrid: Hernando, 1926.

Maurer, Christopher, ed. Federico Garcia Lorca escribe a su familia desde Nueva Yorky La Habana (1929-1930). Poesía. Revista ilustrada de información poética 23-24. Madrid: Ministerio de Cultura, 1986. 67.

Meléndez, Concha. "Federico de Onís y la América Hispana". La Torre (Homenaje a Federico de Onís), 31-36.

Noé, Julio. Antología de la poesía argentina moderna. 1900-1925. Buenos Aires: Nosotros, 1926.

Onís, Federico de. "Current Spanish Literature III. Anthologies of the New Poetry". The Romanic Review XVIII/2 (April-June 1927): 169-173.

Ensayos sobre el sentido de la cultura española. Madrid: Residencia de Estudiantes, 1932. Antologia de la poesía española e hispanoamericana (1882-1932). Madrid: Centro de Estudios Históricos, 1934.

España en América. Estudios, ensayos y discursos sobre temas españoles $e$ hispanoamericanos. Madrid: Publicaciones Universidad de Puerto Rico, 1955. “Ortega, joven". Asomante XII/4 (1956): 7-20. "Unamuno. Introducción". La Torre 35 y 36 (julio-diciembre 1961): 13-20. "Antonio Machado. Introducción". La Torre 45 y 46 (enero-junio 1964): 11-20. "Rubén Darío". La Torre 55 y 56 (enero-junio 1967): 15-35.

Unamuno en su Salamanca. Cartas y recuerdos. Salamanca: Universidad, 1988.

Portolés, José. Medio siglo de filología española (1896-1952) positivismo e idealismo. Madrid: Cátedra, 1986.

Revista de Estudios Hispánicos (Homenaje a Federico de Onís), Año XII, 1985.

Revista Hispánica Moderna (Homenaje a Federico de Onís), Año XXXIV/1-2 (enero-abril 1968).

Río, Angel del. "Notas sobre la crítica y la poesía en Juan Ramón Jiménez. El modernismo". Estudios sobre literatura española contemporánea. Madrid: Gredos, 1966. 124-155. y Bernardete, Mair José. "Federico de Onís". El concepto contemporáneo de España. Antología de ensayos 1895-1931. 1946. Nueva York: Las Américas Publishing Company, 1962. 617-620.

Rius, Luis. León Felipe, poeta de barro. México: Colección Málaga, 1974, $2^{\circ}$ ed. 
Sobejano, Gonzalo y Susana Redondo de Feldman. "Revista Hispánica Moderna". Romanische Forschungen. Frankfurt am Main: Vittorio Klostermann, 1988. 222230.

Soria Olmedo, Andrés. "Introducción”. Gerardo Diego. Poesía española contemporánea. Madrid: Taurus, 1931. 11-64.

Torre, Guillermo de. Historia de las literaturas de vanguardia. 1967. vol. II. Madrid: Guadarrama, 1974.

"Una gran antología poética". Revista de Occidente XIII/CXL (febrero 1935): 222232.

Ucelay, Margarita. "Entidades Hispánicas en los Estados Unidos. The Hispanic Institute in the United States" (1-4). La Estafeta Literaria 488, 489, 490, 491 (15 de marzo, 1 de abril, 15 de abril, 1 de mayo 1972). 